\title{
Action and object naming in physiological aging: an rTMS study
}

\section{Maria Cotelli ${ }^{*}$, Rosa Manenti ${ }^{1}$, Sandra Rosini' ${ }^{1}$, Marco Calabria', Michela Brambilla' ${ }^{1}$, Patrizia Silvia Bisiacchi ${ }^{2}$, Orazio Zanetti ${ }^{1}$ and Carlo Miniussi ${ }^{1,3}$}

\author{
I Istituto Di Ricovero e Cura a Carattere Scientifico, Centro San Giovanni di Dio Fatebenefratelli, Brescia, Italy \\ 2 Department of General Psychology, University of Padua, Italy \\ ${ }^{3}$ Department of Biomedical Sciences and Biotechnologies, National Neuroscience Institute, University of Brescia, Brescia, Italy
}

\section{Edited by:}

Hari S. Sharma, Uppsala University, Sweden

\section{Reviewed by:}

John F. Disterhoft, Northwestern University Medical School, USA

Ashok K. Shetty, Duke University

Medical Center, USA

*Correspondence:

Maria Cotelli, Istituto Di Ricovero e Cura a Carattere Scientifico, Centro San Giovanni di Dio Fatebenefratelli, Via Piastroni, 425125 Brescia, Italy. e-mail: mcotelli@fatebenefratelli.it
Word-retrieval difficulties commonly occur in healthy aging. Recent studies report an improved ability to name pictures after the administration of high-frequency repetitive transcranial magnetic stimulation (rTMS) in healthy younger adults and in patients with neurological disease. The aim of this study was to assess the effect of high-frequency rTMS applied to the dorsolateral prefrontal cortex (DLPFC) on picture naming in healthy older adults. High-frequency rTMS was applied to the left and right DLPFC during object and action naming in 13 healthy older adults. The naming latency for actions was shortened after stimulation of the left and right DLPFC compared to application of the sham stimulation. Stimulation was not observed to have any effect on correctness of naming. Our data demonstrate the involvement of the left and right DLPFC in a sample of healthy aging subjects during an action-naming task. The bilateral involvement of the DLPFC in these participants is discussed together with data on younger adults and on Alzheimer's patients.

\section{Keywords: brain stimulation, naming, HAROLD}

\section{INTRODUCTION}

Several studies have investigated cognitive changes linked to healthy aging and have documented an age-related decline in naming (Goodglass, 1980; Nicholas et al., 1985; LaBarge et al., 1986; Ardilla and Rosselli, 1989; Feyereisen, 1997) and lexical retrieval processing abilities (Nicholas et al., 1985; Bowles et al., 1987; Albert et al., 1988; Au et al., 1995; Ramsay et al., 1999; Barresi et al., 2000; Mackay et al., 2002; Morrison et al., 2003; Connor et al., 2004; Mortensen et al., 2008), generally observed after the age of 70 (Feyereisen, 1997). A number of studies suggest that increased picture-naming errors in older adults reflect impairment in lexical or phonological access rather than in semantic access (Barresi et al., 2000; Mackay et al., 2002; Mortensen et al., 2006). Moreover, differences in the performances of younger and older adult participants on a picture-naming task have also been related to a slowing of the speed of processing with age. In this respect, a number of studies have provided data consistent with the hypothesis that older adults are slower than younger adults in picturenaming tasks (Thomas et al., 1977; Mitchell, 1989; Morrison et al., 2003). However, despite reports of word retrieval difficulties in older adults, age-related difficulties in picture naming have not consistently been identified (Villardita et al., 1985; LaBarge et al., 1986; Flicker et al., 1987). Goulet et al. (1994) argued that different methodological variables such as the age range of participants, the study design, and the type of naming task might account for these different results. Moreover, the material to be named could be different between studies, and action and object naming could give different results. Studies of retrieval abilities by grammatical class provide evidence for dissociation between action and object naming in the healthy aging population. In these studies, action naming was relatively more preserved in older adults than object naming (Nicholas et al., 1997; Barresi et al., 2000). In contrast,
Mackay et al. (2002) demonstrated that when action and object items are carefully matched for difficulty, the aging process affects the naming of actions and objects equally.

Naming difficulty is commonly present in aphasic and demented patients (Robinson et al., 1996; Cappa et al., 1998; Kim and Thompson, 2000; Cotelli et al., 2006a; Crepaldi et al., 2006). Lesion and imaging studies support the hypothesis of a central role of the left prefrontal and parietal areas in the naming of actions (i.e., verb processing) (Daniele et al., 1994; Perani et al., 1999b). However, studies that establish the role of these areas in older adults are still lacking.

Repetitive transcranial magnetic stimulation (rTMS) can induce a brief change in a subject's behavioral performance only if it is applied over an area that is causally engaged in that task being executed. Recent studies reported an improved ability to name pictures after the administration of rTMS over the prefrontal cortex in healthy younger adults and in patients with several types of neurological diseases (Topper et al., 1998; Cappa et al., 2002; Martin et al., 2004; Naeser et al., 2005a, b; Cotelli et al., 2006b, 2008; Finocchiaro et al., 2006). Cappa et al. (2002) reported a selective facilitation in younger adults for action naming when they received rTMS to the left dorsolateral prefrontal cortex (DLPFC). Specifically, they found a shortening in verbal response times compared to sham (i.e., placebo) stimulation. Consistent with these results, Cotelli et al. (2006b, 2008) applied the same protocol in Alzheimer's disease (AD) patients and found that rTMS to the DLPFC improves naming performance in AD patients not only in the early stage (Cotelli et al., 2006b) but also in a more advanced stage of cognitive decline (Cotelli et al., 2008). Importantly, the improvement in $\mathrm{AD}$ patients consisted of an increased correctness score after left and right rTMS compared to the sham stimulation condition. Moreover, in patients in the early stages of cognitive 
decline, rTMS only improved action-naming performance, while both action-and object-naming performance were improved in patients in an advanced stage of cognitive decline.

The purpose of this study was to explore the effects of rTMS applied to the DLPFC on an action and object picture-naming task in older adults. We hypothesized that stimulation of the left DLPFC can generate a facilitatory effect, namely a decrease in the verbal reaction time in action picture naming, as previously found in younger adults. Furthermore, if physiological aging implies hemispheric asymmetry reduction, as previously suggested, we would expect to find facilitation after stimulation of either the left or right DLPFC, as found in previous studies with AD patients (Cotelli et al., 2006b, 2008).

\section{MATERIALS AND METHODS EXPERIMENT 1: BEHAVIORAL ACTION AND OBJECT-NAMING TASK}

The aim of Experiment 1 was to select from a larger set of pictures a congruent subset of stimuli balanced for all variables and verbal reaction time $(\mathrm{vRT})$.

\section{Participants}

Prior to being enrolled in the experiment, participants were administered a standard health history questionnaire and completed a Mini Mental State Examination (MMSE) (Folstein et al., 1975). Potential participants were excluded if they reported a history of neurological disease, cardiovascular disease, psychiatric disorders or alcohol or other substance abuse. Individuals who reported subjective memory complaints or scored below 27 out of 30 on the MMSE were also excluded. Thirty ( 8 male, 22 female) healthy older adults (age 60-81 years, mean 64.1 years, education mean $=13.8$ years) participated in the experiment. All participants were native Italian speakers and had normal or corrected-to-normal vision. All participants were right-handed (Oldfield, 1971). The study was approved by the local ethics committee, and informed consent was obtained from all participants prior to the beginning of the experiment.

\section{Stimuli}

The stimuli used in the action and object picture-naming tasks were taken from the Center for Research in Language-International Picture-Naming Project corpus CRL-IPNP (Bates et al., 2000), which contains 795 black and white two-dimensional line drawings representing actions and objects. These items have been tested and normed in healthy and patient populations across seven different international sites and languages. Items are coded for a number of variables known to influence naming difficulty. These variables include word frequency, age of acquisition, and picture imageability scores; the named variables were tested to see whether they significantly influenced participants' naming performance.

In Experiment 1, we used 54 objects and 54 actions taken from the CRL-IPNP database. None of the action stimuli included in the task were associated with the selected objects. The nouns and verbs corresponding to the set of objects and actions used were matched for target word frequency and length. The frequency, length of the target word, visual complexity and imageability of the pictures were matched and counterbalanced between the experimental blocks. Ten additional objects and actions were used for a practice block (5 actions and 5 objects).

\section{Procedure}

Subjects sat in front of a 17 -inch monitor controlled by a personal computer running Presentation software ${ }^{1}$. The trial structure of Experiment 1 is illustrated in Figure 1. After a frame that indicated the category of the stimulus to the subject ("ACTION" or "OBJECT"), a sound $50 \mathrm{~ms}$ in duration was presented at the onset of a centrally located fixation cross that was present for $1000 \mathrm{~ms}$. After the disappearance of the fixation cross, the stimulus was presented and remained on the screen for $1000 \mathrm{~ms}$. A blank screen followed for a time varying from 4000 to $5000 \mathrm{~ms}$. The subject's task was to accurately name as fast as possible the stimuli appearing on the computer screen. Verbal responses were recorded and digitized at $44.1 \mathrm{kHz}$ using the program GoldWave (V. 5.12) ${ }^{2}$. The responses were then analyzed off-line for accuracy and vRTs. For each stimulus, we calculated the mean vRT and the mean response accuracy percentage.

\section{Results}

The 54 actions were, on average, named after $1132 \mathrm{~ms}( \pm 280)$, whereas the 54 objects required $823 \mathrm{~ms}( \pm 154)$ to be correctly named. The mean accuracy was $90 \%( \pm 14)$ for actions and $97 \%( \pm 4)$ for objects.

Based on these results, we decided to exclude the actions that required a vRT higher than $1692 \mathrm{~ms}$ (i.e., mean vRT plus 2 standard deviations) or with a mean accuracy lower than $85 \%$. We excluded objects with vRTs higher than 1131 (i.e., mean vRT plus 2 standard deviations) or with a mean accuracy lower than $90 \%$.

The obtained subset of stimuli comprised 42 actions and 42 objects. Within this final set, actions were named after $1070 \mathrm{~ms}$ $( \pm 252)$, whereas objects required $777 \mathrm{~ms}( \pm 108)$ to be correctly named. The mean accuracy was $95 \%( \pm 5)$ for actions and $99 \%$ $( \pm 2)$ for objects. The new sets of stimuli were still matched for frequency and length.

\section{EXPERIMENT 2: rTMS EXPERIMENT Participants}

All the exclusion criteria used in Experiment 1 were also used in Experiment 2. In addition, a neuropsychological battery was applied, and a pathological score in at least one of the tests was a further exclusion criterion. Thirteen ( 4 male, 9 female) healthy older adults (age 65-78 years, mean 70.2 years, education mean $=13.8$ years) participated in the rTMS experiment. All participants were native Italian speakers and had normal or corrected-to-normal vision. All participants were right-handed (Oldfield, 1971) and had no contraindications for rTMS (Rossi et al., 2009). The study was approved by the local ethics committee, participants were informed about the possible risk of rTMS, and informed consent was obtained.

The neuropsychological test battery included measures to assess non-verbal reasoning (Raven-Colored Progressive Matrices), language comprehension (Token Test), verbal fluency (phonemic and semantic), memory (Story Recall, Rey-Osterrieth Complex Figure Recall, Digit Span, Spatial Span), visuo-spatial abilities (ReyOsterrieth Complex Figure, Copy), attention and executive functions (Trail-Making Test A and B). All the tests were administered and scored according to standard procedures (Lezak et al., 2004).

${ }^{1}$ www.neurobs.com

${ }^{2}$ www.goldwave.com 


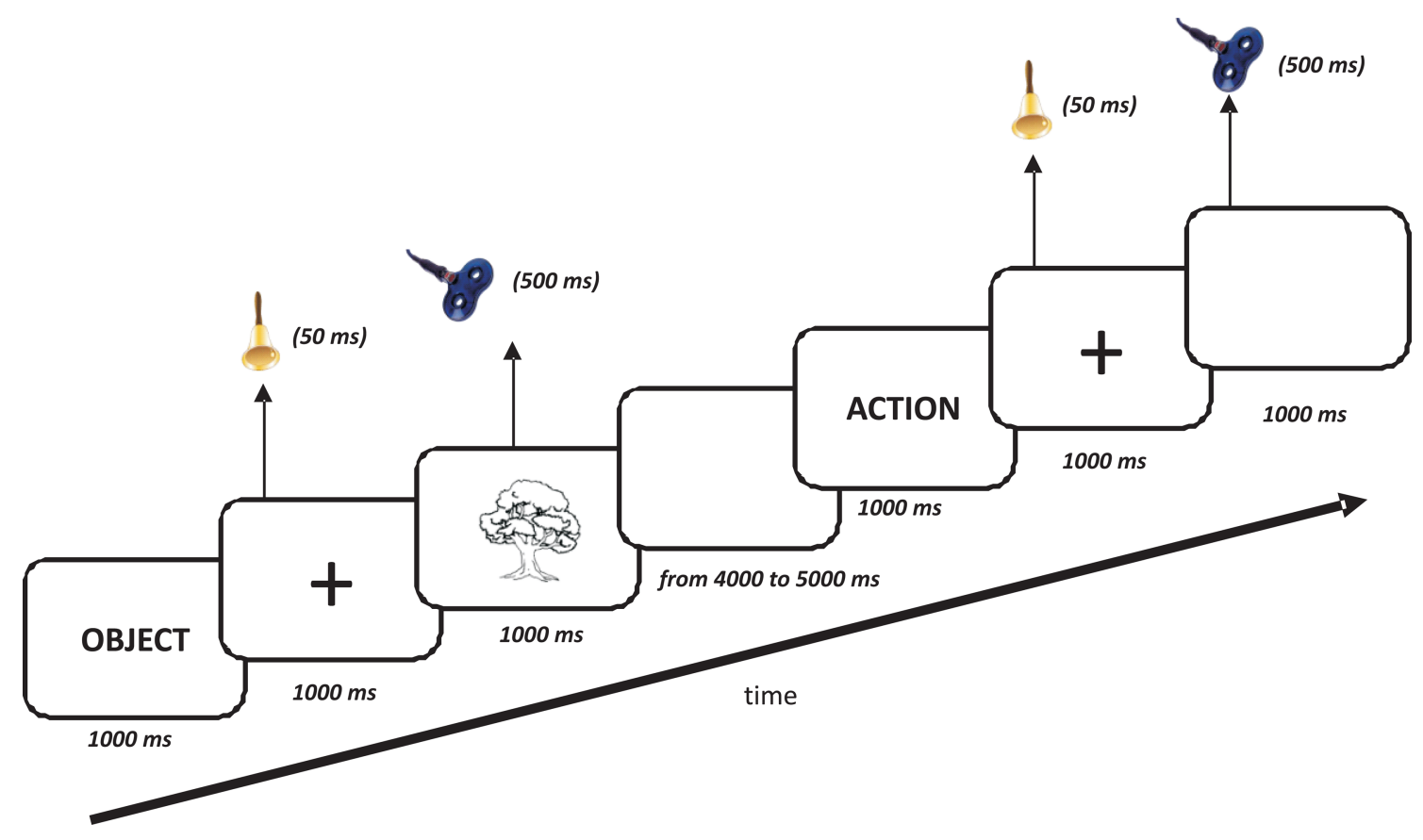

FIGURE 1 |Time course of the experiment. The initial frame indicated the category of the next stimulus to the subject ("ACTION" or "OBJECT"). A sound (50 ms in duration) was presented at the onset of a centrally located fixation cross (1000 ms duration) that preceded the picture. The picture was

In addition, some subtests of the Battery for Analysis of Aphasic Deficits (BADA) were applied (Miceli et al., 1994). The results of the cognitive assessment are presented in Table $\mathbf{1 .}$

\section{Stimuli}

Experiment 2 used the 84 items ( 42 actions and 42 objects) selected from the previous experiment. None of the action stimuli included in this task were associated with the selected objects. The nouns and verbs corresponding to the set of objects and actions were matched for target word frequency and length.

The items were divided into three blocks designed for the three stimulation conditions (left DLPFC, right DLPFC, and sham stimulation). The frequencies and lengths of the target words were counterbalanced in the experimental blocks. The visual complexity and imageability of the pictures were also matched between blocks. Ten additional objects and actions were used for a practice block (5 actions and 5 objects).

\section{Procedure}

The procedures of the behavioral task were exactly the same as those used in Experiment 1 (see Figure 1). The experiment included three blocks corresponding to three stimulation sites, left and right DLPFC and sham stimulation, and presentation orders were counterbalanced across subjects. For the sham control condition, a 3-cm-thick piece of plywood was applied to the coil (Harris and Miniussi, 2003; Rossi et al., 2007) so that no magnetic fields reached the cortex. For the sham condition, the junction of the two coil wings was placed above the vertex (CZ in the EEG 10/20 international system) using the same procedure as for the real rTMS. For left and right DLPFC, present on the monitor for 1000 ms while trains of rTMS $(500 \mathrm{~ms}$, $20 \mathrm{~Hz}, 10 \%$ subthreshold) were delivered simultaneously with the picture presentation. Verbal reaction times were recorded with a microphone.

Table 1 | Neuropsychological data of the older adults who participated in Experiment 2.

\begin{tabular}{|c|c|c|}
\hline & Raw scores & Cut-off \\
\hline \multicolumn{3}{|l|}{ SCREENING FOR DEMENTIA } \\
\hline MMSE & $29.5 / 30$ & 24 \\
\hline \multicolumn{3}{|l|}{ NON-VERBAL REASONING } \\
\hline Raven-colored progressive matrices & $30.9 / 36$ & 17.5 \\
\hline \multicolumn{3}{|l|}{ MEMORY } \\
\hline Story recall & $15.2 / 28$ & 7.5 \\
\hline Rey-Osterrieth complex figure, recall & $14.6 / 36$ & 9.46 \\
\hline Digit span & 5.7 & 3.75 \\
\hline Spatial span & 4.9 & 3.55 \\
\hline \multicolumn{3}{|l|}{ PRAXIA } \\
\hline Rey-Osterrieth complex figure, copy & $33.1 / 36$ & 28.87 \\
\hline \multicolumn{3}{|l|}{ EXECUTIVE FUNCTION } \\
\hline Trail-making test A (s) & 40.2 & 93 \\
\hline Trail-making test B (s) & 117.1 & 282 \\
\hline \multicolumn{3}{|l|}{ LANGUAGE } \\
\hline Token test & $33.6 / 36$ & 26.5 \\
\hline Fluency, phonemic & 39.6 & 16 \\
\hline Fluency, semantic & 45.3 & 24 \\
\hline Oral object comprehension (BADA) & $39.9 / 40$ & \\
\hline Oral action comprehension (BADA) & $19.9 / 20$ & \\
\hline Written object comprehension (BADA) & $39.9 / 40$ & \\
\hline Written action comprehension (BADA) & $19.9 / 20$ & \\
\hline Oral object naming (BADA) & $29.2 / 30$ & \\
\hline Oral action naming (BADA) & $27.0 / 28$ & \\
\hline
\end{tabular}


the Talairach coordinates of cortical sites underlying the coil were estimated for each subject by the SofTaxic Evolution Navigator system (V. 2.0) ${ }^{3}$. This system was used to identify the stimulation site on the scalp above Brodmann area 8 (Talairach coordinates $X= \pm 35$, $Y=24, Z=48$, middle frontal) as in previous studies (Cappa et al., 2002; Cotelli et al., 2006b, 2008). The SofTaxic Navigator system permits the estimation of the MRI volume from the head, allowing us to guide the rTMS coil positioning in subjects for whom MRIs were unavailable. The estimated MRIs are automatically calculated using a warping procedure that operates on a generic MRI volume (template) on the basis of a set of points digitized from the subject's scalp. The accuracy of this procedure has been evaluated on 28 healthy adults (mean age 35 years) having own MRIs used as gold standard. In this evaluation, the TMS stimulation brain site was localized using both own and estimated MRIs, while the position of the TMS coil was kept fixes onto the subject's scalp. The results indicate a mean error of $2.11 \mathrm{~mm}$, with a standard deviation of $2.04 \mathrm{~mm}$, lower than TMS spatial resolution (unpublished data). To stimulate the DLPFC, we used a $70 \mathrm{~mm}$ figure-eight coil and placed the junction of the two coil wings above the target point. rTMS was delivered for $500 \mathrm{~ms}$ from the onset of the visual stimulus using a frequency of $20 \mathrm{~Hz}$. We decided to stimulate for the first $500 \mathrm{~ms}$ with a frequency of $20 \mathrm{~Hz}$ because we were looking for a facilitation effect, as reported in previous studies (Wassermann, 1998; Machii et al., 2006). The stimulation intensity used during the experiment was set at $90 \%$ of each subject's resting motor threshold. These parameters are in line with safety recommendations for rTMS (Rossi et al., 2009), and none of the subjects showed side effects of stimulation.

\section{Results}

We separately analyzed both vRTs and accuracy using a repeatedmeasures ANOVA with stimulus category (action and object) and site (sham, left and right) as factors. With respect to accuracy,

${ }^{3}$ www.emsmedical.net this analysis only showed a significant effect of stimulus category $[F(1,12)=23.38, p=0.0004]$, indicating a higher accuracy for objects $($ mean $=98.7 \pm 0.3)$ than for actions $($ mean $=88.4 \pm 2)$. Conversely, with respect to vRTs, this analysis indicated significant effects of both stimulus category $[F(1,12)=94.01, p<0.0001]$ and the interaction of stimulus category with site $[F(2,24)=5.46, p=0.01]$.

Post hoc analysis, Fisher's Least Significant Difference (LSD) test, revealed that for actions, naming performance was better during stimulation of both left $($ mean $=963.3 \pm 20, p=0.003)$ and right (mean $=975.5 \pm 40, p=0.006$ ) DLPFC than during sham stimulation $($ mean $=1077.5 \pm 36)$. However, this was not true for objects, for which performance did not differ significantly between conditions, as shown in Figure 2.

\section{DISCUSSION}

The primary finding of this study is that rTMS applied to the DLPFC improves action-naming performance in older adults. This finding provides further direct evidence for a causal role of DLPFC in naming, consistent with the results of previous studies on younger adults (Cappa et al., 2002). While the rTMS effect in healthy younger adults was limited to left-sided stimulation, the facilitation in our elderly sample was bilateral. Functional neuroimaging studies have shown that older adults tend to recruit regions of the contralateral hemisphere in addition to regions of the specialized hemisphere used by younger adults when performing cognitive tasks (Grady et al., 1998; D'Esposito et al., 1999; Grady, 2000; Rypma and D'Esposito, 2000; Cabeza et al., 2002; Logan et al., 2002; Stebbins et al., 2002; Wierenga et al., 2008). The presence of a facilitation effect after right or left DLPFC rTMS in older adults could be attributed to the presence of a compensatory mechanism based on the recruitment of right hemispheric resources to maintain task performance despite the possible reduction in neural efficacy of a distributed naming network. A shift from unilateral to bilateral engagement is consistent with Cabeza's (2002) model of hemispheric asymmetry reduction in older adults (HAROLD). The HAROLD hypothesis proposes that

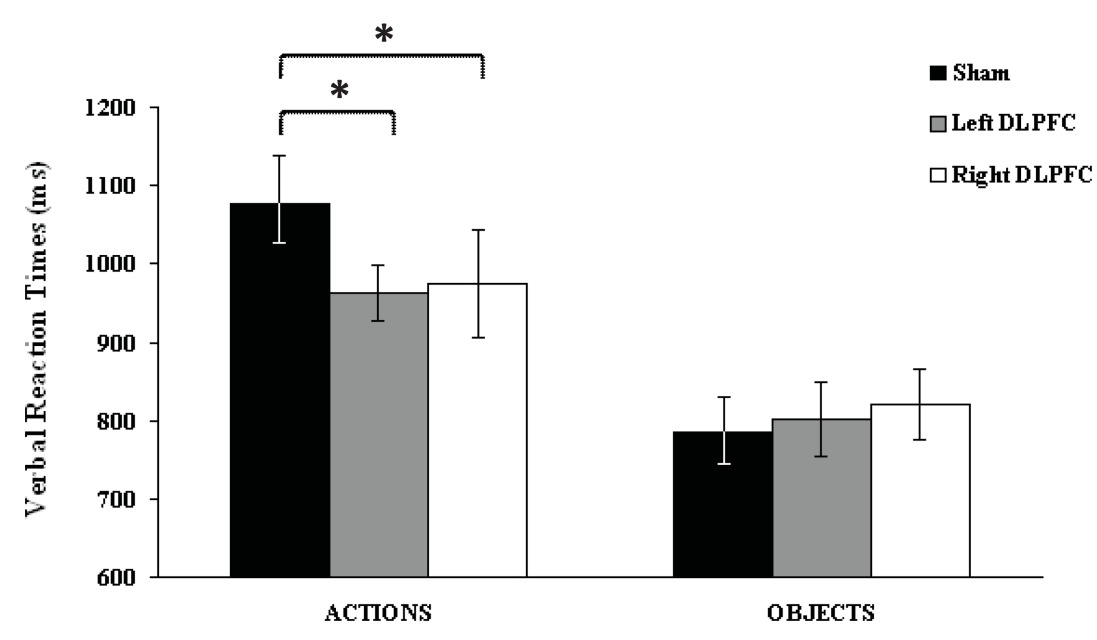

FIGURE 2 |Verbal reaction times (vRTs) following each stimulation condition, plotted separately for action and object stimuli. Asterisks indicate significant effects $(p<0.05)$. vRTs for actions were consistently faster during left and right dorsolateral prefrontal cortex than during sham stimulation. No significant differences were observed for object naming. Errors bars indicate mean standard error. 
bilateral activation increases with age. There is evidence from many cognitive tasks supporting the HAROLD hypothesis (Grady et al., 1994; Rossi et al., 2001; Cabeza et al., 2002; Rowe et al., 2006), although the importance of these reduced lateralization remains unclear.

In the case of language, the right hemisphere has traditionally been assigned a crucial role in supporting performance after left hemispheric damage (Vandenbulcke et al., 2005). Consistent with this idea, a recent study reported that older participants activate a larger frontal network than younger adults during word retrieval and that they show less lateralization of activity (Wierenga et al., 2008). In the present study, we reported a facilitation effect following stimulation of the left or right DLPFC and showed that this effect is consistent with recent findings in $\mathrm{AD}$ in which stimulation of both DLPFCs improved picture naming compared to placebo stimulation (Cotelli et al., 2006b, 2008). In AD patients, DLPFC has been specifically shown to improve the number of correct responses, whereas we found a shortening of vRT in our older adult group. This difference could be explained by the presence of a "ceiling" effect that decreases the likelihood of finding accuracy effects in these healthy subjects.

The use of rTMS involves the discharge of a transient electromagnetic field through the skull. Rapidly changing magnetic fields induce electric currents in the brain, which in turn produce transynaptic depolarization of groups of neurons located in the superficial cortical layers (Heller and van Hulsteyn, 1992). The effect of rTMS is believed to result from activation of these neurons. rTMS has also been shown to be able to influence the activity of brain centers distant from the stimulated site through the activation of cortico-cortical or cortico-subcortical networks (Bestmann et al., 2008; Miniussi and Thut, 2010); this observation actually provided the starting point for clinical application of rTMS. The fact that rTMS can facilitate a network rather than a single area is also consistent with a large number of focal lesion and neuroimaging studies that demonstrate that the ability to name an action or an object depends on a wide and complex cerebral network (Perani et al., 1999a; Damasio et al., 2001; Cappa and

\section{REFERENCES}

Albert, M. S., Heller, H. S., and Milberg, W. (1988). Changes in naming ability with age. Psychol. Aging 3, 173-178.

Ardilla, A., and Rosselli, M. (1989). Neuropsychological characteristics of normal aging. Dev. Neuropsychol. 5, 307-320.

Au, R., Joung, P., Nicholas, M., Obler, L. K., Kass, R., and Albert, M. L. (1995). Naming ability across the adult life span. Aging Cogn. 2, 300-311.

Barresi, B. A., Nicholas, M., Connor, L. T., Obler, L., and Albert, M. L. (2000). Semantic degradation and lexical access in age-related naming failures. Aging Neuropsychol. Cogn. 7, 169-178.

Bates, E., Andonova, E., D’Amico, S., Jacobsen, T., Kohnert, K., Lu, C. C., Székely, A., Wicha, N., Federmeier, K., Herron, D., Iyer, G., Pechmann, T., Devescovi, A., Mehotcheva, T., and Pleh, C. (2000). Introducing the CRL
International Picture-Naming Project (CRL-IPNP). Center for Research in Language Newsletter La Jolla:University of California San Diego 12.

Bestmann, S., Ruff, C. C., Blankenburg, F., Weiskopf, N., Driver, J., and Rothwell, J. C. (2008). Mapping causal interregional influences with concurrent TMS-fMRI. Exp. Brain Res. 191, 383-402.

Bowles, N. L., Obler, L. K., and Albert, M. L. (1987). Naming errors in healthy aging and dementia of the Alzheimer type. Cortex 23, 519-524.

Cabeza, R. (2002). Hemispheric asymmetry reduction in older adults: the HAROLD model. Psychol. Aging. 17, 85-100.

Cabeza, R., Anderson, N. D., Locantore, J. K., and McIntosh, A. R. (2002). Aging gracefully: compensatory brain activity in high-performing older adults. Neuroimage 17, 1394-1402.
Perani, 2003; DeLeon et al., 2007). These observations have led to the hypothesis that neural networks subserving naming involve numerous cerebral areas including the bilateral occipito-temporoparietal and left frontal areas.

The present results showed a reduction in vRTs in actionnaming performance in older adults. The reduction in vRTs suggests that this effect is related to a facilitation of the task that involves recalling the semantic representation of the action and that this facilitation speeds up task execution. Several studies have demonstrated that the reduction in naming efficacy that occurs in older adults reflects inefficient access to semantic knowledge rather than a true loss of semantic representations (Barresi et al., 2000; Mackay et al., 2002; Mortensen et al., 2006). In our experiment, brain stimulation-induced cortical modulation of synaptic efficacy and connectivity occurs, potentiating the system within the language network and thus leading to more effective processing. These observations lead us to suggest that the improvement in performance observed after DLPFC stimulation may reflect a facilitation of lexical retrieval processes. Thus, these data confirm the hypothesis that the reduced efficiency in naming that occurs in healthy aging is due to defective access rather than to semantic loss (Jefferies et al., 2007).

In conclusion, the present study confirms that rTMS is a useful tool that can complement traditional neuroimaging approaches in the investigation of age-dependent modifications of the causal engagement of cortical brain regions. Moreover, age-related decline in performance on an action-naming task seems to be the consequence of a slowing down of lexical access. Finally, our findings further support the HAROLD model, which posits a bilateral involvement of DLPFC in older adults compared with a left-sided involvement of this area in younger adults.

\section{ACKNOWLEDGMENTS}

We wish to thank the participants in the study for their patience. This research was supported by a project grant from the "Fondazione della Comunità Bresciana-onlus".
Cappa, S. F., Binetti, G., Pezzini, A. Padovani, A., Rozzini, L., and Trabucchi, M. (1998). Object and action naming in Alzheimer's disease and frontotemporal dementia. Neurology 50, 351-355.

Cappa, S. F., and Perani, D. (2003). The neural correlates of noun and verb processing. J. Neurolinguistics 16, 183-189.

Cappa, S. F., Sandrini, M., Rossini, P. M., Sosta, K., and Miniussi, C. (2002). The role of the left frontal lobe in action naming: rTMS evidence. Neurology 59, 720-723.

Connor, L. T., Spiro, A. III, Obler, L. K., and Albert, M. L. (2004). Change in object naming ability during adulthood. J. Gerontol. B. Psychol. Sci. Soc. Sci. 59, P203-P209.

Cotelli, M., Borroni, B., Manenti, R., Alberici, A., Calabria, M., Agosti, C., Arevalo, A., Ginex, V., Ortelli, P.,
Binetti, G., Zanetti, O., Padovani, A., and Cappa, S. F. (2006a). Action and object naming in frontotemporal dementia, progressive supranuclear palsy, and corticobasal degeneration. Neuropsychology 20, 558-565.

Cotelli, M., Manenti, R., Cappa, S. F., Geroldi, C., Zanetti, O., Rossini, P. M., and Miniussi, C. (2006b). Effect of transcranial magnetic stimulation on action naming in patients with Alzheimer disease. Arch. Neurol. 63, 1602-1604.

Cotelli, M., Manenti, R., Cappa, S. F., Zanetti, O., and Miniussi, C. (2008). Transcranial magnetic stimulation improves naming in Alzheimer disease patients at different stages of cognitive decline. Eur. J. Neurol. 15, 1286-1292.

Crepaldi, D., Aggujaro, S., Arduino, L. S., Zonca, G., Ghirardi, G., Inzaghi, M. G., Colombo, M., Chierchia, G., 
and Luzzatti, C. (2006). Noun-verb dissociation in aphasia: the role of imageability and functional locus of the lesion. Neuropsychologia 44, 73-89.

D’Esposito, M.,Zarahn, E., Aguirre, G. K. and Rypma, B. (1999). The effect of normal aging on the coupling of neural activity to the bold hemodynamic response. Neuroimage 10, 6-14.

Damasio, H., Grabowski, T. J., Tranel, D., Ponto, L. L., Hichwa, R. D., and Damasio, A. R. (2001). Neural correlates of naming actions and of naming spatial relations. Neuroimage 13, 1053-1064.

Daniele, A., Giustolisi, L., Silveri, M. C., Colosimo, C., and Gainotti, G. (1994). Evidence for a possible neuroanatomical basis for lexical processing of nouns and verbs. Neuropsychologia 32, 1325-1341.

DeLeon, J., Gottesman, R. F., Kleinman, J. T., Newhart, M., Davis, C., HeidlerGary, J., Lee, A., and Hillis, A. E. (2007). Neural regions essential for distinct cognitive processes underlying picture naming. Brain 130, 1408-1422.

Feyereisen, P. (1997). A meta-analytic procedure shows an age-related decline in picture naming: comments on Goulet, Ska, and Kahn (1994). J. Speech Lang. Hear. Res. 40, 1328-1333.

Finocchiaro, C., Maimone, M., Brighina, F., Piccoli, T., Giglia, G., and Fierro, B. (2006). A case study of primary progressive aphasia: improvement on verbs after rTMS treatment. Neurocase 12, 317-321.

Flicker, C., Ferris, S. H., Crook, T., and Bartus, R. T. (1987). Implications of memory and language dysfunction in the naming deficit of senile dementia. Brain Lang. 31, 187-200.

Folstein, M. F., Folstein, S.E., and McHugh, P. R. (1975). "Mini-mental state”. A practical method for grading the cognitive state of patients for the clinician. J. Psychiatr. Res. 12, 189-198.

Goodglass, H. (1980). "Naming disorders in aphasia and aging," in Language and Comunication in the Ederly, eds L. K. Obler and M. L. Albert (Toronto: Lexington Books), 37-45.

Goulet, P., Ska, B., and Kahn, H. J. (1994). Is there a decline in picture naming with advancing age? J. Speech Hear. Res. 37, 629-644.

Grady, C. L. (2000). Functional brain imaging and age-related changes in cognition. Biol. Psychol. 54, 259-281.

Grady, C. L., Maisog, J. M., Horwitz, B., Ungerleider, L. G., Mentis, M. J., Salerno, J. A., Pietrini, P., Wagner, E., and Haxby, J. V. (1994). Age-related changes in cortical blood flow activation during visual processing of faces and location. J. Neurosci. 14, 1450-1462.

Grady, C. L., McIntosh, A. R., Bookstein, F., Horwitz, B., Rapoport, S. I., and Haxby, J. V. (1998). Age-related changes in regional cerebral blood flow during working memory for faces. Neuroimage 8, 409-425.

Harris, I. M., and Miniussi, C. (2003) Parietal lobe contribution to mental rotation demonstrated with rTMS. J. Cogn. Neurosci. 15, 315-323.

Heller, L., and van Hulsteyn, D. B. (1992) Brain stimulation using electromagnetic sources: theoretical aspects. Biophys. J. 63, 129-138.

Jefferies, E., Baker, S. S., Doran, M. and Ralph, M. A. (2007). Refractory effects in stroke aphasia: a consequence of poor semantic control. Neuropsychologia 45, 1065-1079.

Kim, M., and Thompson, C. K. (2000) Patterns of comprehension and production of nouns and verbs in agrammatism: implications for lexical organization. Brain Lang. 74, 1-25.

LaBarge, E., Edwards, D., and Knesevich, J. W. (1986). Performance of normal elderly on the boston naming test. Brain Lang. 27, 380-384.

Lezak, M., Howieson, D., and Loring, D. W. (2004). Neuropsychological Assessment, 4th Edn. Oxford: University Press.

Logan, J. M., Sanders, A. L., Snyder, A. Z., Morris, J.C., and Buckner, R. L. (2002). Under-recruitment and non-selective recruitment: dissociable neural mechanisms associated with aging. Neuron 33, 827-840

Machii, K., Cohen, D., Ramos-Estebanez, C., and Pascual-Leone, A. (2006). Safety of rTMS to non-motor cortical areas in healthy participants and patients. Clin. Neurophysiol. 117 455-471.

Mackay, A. I., Connor, L. T., Albert, M. L., and Obler, L. K. (2002). Noun and verb retrieval in healthy aging. J. Int. Neuropsychol. Soc. 8, 764-770.

Martin, P. I., Naeser, M. A., Theoret, H. Tormos, J. M., Nicholas, M., Kurland, J., Fregni, F., Seekins, H., Doron, K., and Pascual-Leone, A. (2004). Transcranial magnetic stimulation as a complementary treatment for aphasia. Semin. Speech Lang. 25, 181-191.

Miceli, G., Laudanna, A., Burani, C., and Papasso, R. (1994). Batteriaperl'Analisi dei Deficit Afasici. B.A.D.A. (Battery for Analysis of Aphasic Deficits). Milano: CEPSAG, Università Cattolica del Sacro Cuore.

Miniussi, C., and Thut, G. (2010). Combining TMS and EEG offers new prospects in cognitive neuroscience. Brain Topogr. 22, 249-256.

Mitchell, D. B. (1989). How many memory systems? Evidence from aging. $J$.
Exp. Psychol. Learn Mem. Cogn. 15, 31-49.

Morrison, C.M., Hirsh, K.W., and Duggan, G.B. (2003).Age of acquisition, ageing, and verb production: normative and experimental data. Q. J. Exp. Psychol. A. 56, 705-730.

Mortensen, L., Meyer, A. S., and Humphreys, G. W. (2006). Age-related effects on speech production: a review. Lang. Cogn. Process. 21, 238-290.

Mortensen, L., Meyer, A. S., and Humphreys, G. W. (2008). Speech planning during multiple-object naming: effects of ageing. Q. J. Exp. Psychol (Colchester) 61, 1217-1238.

Naeser, M. A., Martin, P. I., Nicholas, M., Baker, E. H., Seekins, H., HelmEstabrooks, N., Cayer-Meade, C. Kobayashi, M., Theoret, H., Fregni, F., Tormos, J. M., Kurland, J., Doron, K. W., and Pascual-Leone, A. (2005a). Improved naming after TMS treatments in a chronic, global aphasia patient - case report. Neurocase 11 182-193.

Naeser, M. A., Martin, P. I., Nicholas, M. Baker, E. H., Seekins, H., Kobayashi, M., Theoret, H., Fregni, F., MariaTormos, J., Kurland, J., Doron, K. W., and Pascual-Leone, A. (2005b). Improved picture naming in chronic aphasia after TMS to part of right Broca's area: an open-protocol study. Brain Lang. 93, 95-105.

Nicholas, M., Barth, C., Obler, L. K., Au, R., and Albert, M. L. (1997). "Naming in normal aging and dementia of the Alzheimer's type," in: Anomia: Neuroanatomical and Cognitive Correlates, ed.H.G.A. Wingfield (New York: Academic Press), 166-188.

Nicholas, M., Obler, L., Albert, M., and Goodglass, H. (1985). Lexical retrieval in healthy aging. Cortex 21, 595-606.

Oldfield, R. C. (1971). The assessment and analysis of handedness: the Edinburgh inventory. Neuropsychologia 9 , 97-113.

Perani, D., Cappa, S. F., Schnur, T. Tettamanti, M., Collina, S., Rosa, M. M., and Fazio, F. (1999a). The neural correlates of verb and noun processing. A PET study. Brain 122(Pt 12), 2337-2344.

Perani, D., Schnur, T., Tettamanti, M., Gorno-Tempini, M., Cappa, S. F., and Fazio, F. (1999b). Word and picture matching: a PET study of semantic category effects. Neuropsychologia 37, 293-306.

Ramsay, C. B., Nicholas, M., Au, R., Obler, L. K., and Albert, M. L. (1999). Verb naming in normal aging. Appl. Neuropsychol. 6, 57-67.

Robinson, K. M., Grossman, M., WhiteDevine, T., and D’Esposito, M. (1996). Category-specific difficulty naming with verbs in Alzheimer's disease. Neurology 47, 178-182.

Rossi, S., Cappa, S. F., Babiloni, C. Pasqualetti, P., Miniussi, C., Carducci, F., Babiloni, F., and Rossini, P. M. (2001). Prefrontal [correction of prefontal] cortex in long-term memory: an "interference" approach using magnetic stimulation. Nat. Neurosci. 4, 948-952.

Rossi, S., Ferro, M., Cincotta, M. Ulivelli, M., Bartalini, S., Miniussi, C., Giovannelli, F., and Passero, S. (2007). A real electro-magnetic placebo (REMP) device for sham transcranial magnetic stimulation (TMS). Clin. Neurophysiol. 118 709-716.

Rossi, S., Hallett, M., Rossini, P.M. Pascual-Leone, A., and Safety of TMS Consensus Group (2009). Safety, ethical considerations, and application guidelines for the use of transcrania magnetic stimulation in clinical practice and research. Clin. Neurophysiol. 120, 2008-2039.

Rowe, J. B., Siebner, H., Filipovic, S. R., Cordivari, C., Gerschlager, W., Rothwell,J., and Frackowiak, R. (2006). Aging is associated with contrasting changes in local and distant cortical connectivity in the human motor system. Neuroimage 32, 747-760.

Rypma, B., and D'Esposito, M. (2000). Isolating the neural mechanisms of age-related changes in human working memory. Nat. Neurosci. 3, 509-515.

Stebbins, G. T., Carrillo, M. C., Dorfman, J., Dirksen, C., Desmond, J. E., Turner, D. A., Bennett, D. A., Wilson, R. S., Glover, G., and Gabrieli, J. D. (2002). Aging effects on memory encoding in the frontal lobes. Psychol. Aging 17, 44-55.

Thomas, J. C., Fozard, J. L., and Waugh, N. C. (1977). Age-related differences in naming latency. Am. J. Psychol. 90, 499-509.

Topper, R., Mottaghy, F. M., Brugmann, M., Noth, J., and Huber, W. (1998). Facilitation of picture naming by focal transcranial magnetic stimulation of Wernicke's area. Exp. Brain Res. 121, 371-378.

Vandenbulcke, M., Peeters, R., Van Hecke, P., and Vandenberghe, R. (2005). Anterior temporal laterality in primary progressive aphasia shifts to the right. Ann. Neurol. 58, 362-370.

Villardita, C., Cultrera, S., Cupone, V., and Mejia, R. (1985). Neuropsychological test performances and normal aging. Arch. Gerontol. Geriatr. 4, 311-319.

Wassermann, E. M. (1998). Risk and safety of repetitive transcranial magnetic stimulation: report and suggested guidelines from the international 
workshop on the safety of repetitive transcranial magnetic stimulation, June 5-7, 1996. Electroencephalogr. Clin. Neurophysiol. 108, 1-16.

Wierenga, C.E., Benjamin, M., Gopinath, K., Perlstein, W. M., Leonard, C. M., Rothi, L. J., Conway, T., Cato, M. A., Briggs, R., and Crosson, B. (2008). Age-related changes in word retrieval: role of bilateral frontal and subcortical networks. Neurobiol. Aging 29, 436-451.

Conflict of Interest Statement: The authors declare that the research was conducted in the absence of any commercial or financial relationships that could be construed as a potential conflict of interest.
Received: 26 July 2010; accepted: 08 November 2010; published online: 24 November 2010.

Citation: Cotelli M, Manenti R, Rosini S, Calabria M, Brambilla M, Bisiacchi PS, Zanetti $O$ and Miniussi C (2010) Action and object naming in physiological aging: an rTMS study. Front. Ag. Neurosci. 2:151. doi: 10.3389/fnagi.2010.00151
Copyright $@ 2010$ Cotelli, Manenti, Rosini, Calabria, Brambilla, Bisiacchi, Zanettiand Miniussi. This is an open-access article subject to an exclusive license agreement between the authors and the Frontiers Research Foundation, which permits unrestricted use, distribution, and reproduction in any medium, provided the original authors and source are credited. 